DR. JENNY PUI SHAN WONG (Orcid ID : 0000-0002-8729-8166)

DR. NICOLA CARSLAW (Orcid ID : 0000-0002-5290-4779)

Article type : Original Article

Mail id: jabbatt@chem.utoronto.ca

\title{
Observations and impacts of bleach washing on indoor chlorine chemistry
}

\author{
J.P.S Wong, ${ }^{\text {a }}$ N. Carslaw, ${ }^{\text {b }}$ R. Zhao, ${ }^{c}$ S. Zhou, ${ }^{d}$ and J.P.D. Abbatt ${ }^{\mathrm{d}, *}$
}

*to whom correspondence should be addressed

${ }^{a}$ School of Earth and Atmospheric Sciences, Georgia Institute of Technology, 311 Ferst Drive, Atlanta, GA 30331 USA

${ }^{\mathrm{b}}$ Environment Department, University of York, Wentworth Way, Heslington, York YO10 5NG, UK

${ }^{\mathrm{C}}$ Division of Chemistry and Chemical Engineering, California Institute of Technology, $1200 \mathrm{E}$

California Blvd, Pasadena, CA 91125 USA

${ }^{\mathrm{d}}$ Department of Chemistry, University of Toronto, 80 St. George Street, Toronto, ON M5S 3H6

Canada

\section{Abstract}

Ambient levels of chlorinated gases and aerosol components were measured by on-line chemical ionization and aerosol mass spectrometers after an indoor floor was repeatedly washed with a commercial bleach solution. Gaseous chlorine $\left(\mathrm{Cl}_{2}, 10\right.$ 's of ppbv) and hypochlorous acid $(\mathrm{HOCl}, 100$ 's of ppbv) arise after floor washing, along with nitryl chloride $\left(\mathrm{CINO}_{2}\right)$, dichlorine monoxide $\left(\mathrm{Cl}_{2} \mathrm{O}\right)$ and chloramines $\left(\mathrm{NHCl}_{2}, \mathrm{NCl}_{3}\right)$. Much higher mixing ratios would prevail in a room with lower and more commonly encountered air exchange rates than that observed in the study $\left(12.7 \mathrm{~h}^{-1}\right)$. Coincident This article has been accepted for publication and undergone full peer review but has not been through the copyediting, typesetting, pagination and proofreading process, which may lead to differences between this version and the Version of Record. Please cite this article as doi: 10.1111/ina.12402

This article is protected by copyright. All rights reserved. 
with the formation of gas-phase species, particulate chlorine levels also rise. $\mathrm{Cl}_{2}, \mathrm{ClNO}_{2}, \mathrm{NHCl}_{2}$ and $\mathrm{NCl}_{3}$ exist in the headspace of the bleach solution whereas $\mathrm{HOCl}$ was only observed after floor washing. $\mathrm{HOCl}$ decays away 1.4 times faster than the air exchange rate, indicative of uptake onto room surfaces and consistent with the well-known chlorinating ability of $\mathrm{HOCl}$. Photochemical box modeling captures the temporal profiles of $\mathrm{Cl}_{2}$ and $\mathrm{HOCl}$ very well, and indicates that the $\mathrm{OH}, \mathrm{Cl}$ and $\mathrm{ClO}$ gas-phase radical concentrations in the indoor environment could be greatly enhanced $\left(>10^{6}\right.$ and $10^{5} \mathrm{~cm}^{-3}$ for $\mathrm{OH}$ and $\mathrm{Cl}$, respectively) in such washing conditions, dependent on the amount of indoor illumination.

\section{Practical Implications}

Washing a floor with bleach leads to the introduction of a number of chlorinated gases to the room, including hypochlorous acid and chlorine. The chlorine levels of particles in the room also rise. The hypochlorous acid is observed to decay rapidly, implying uptake to room surfaces. Photochemical modeling indicates that significant levels of gas phase radicals may form, dependent upon the amount of room light. Overall, bleach washing leads to enhanced oxidation of not only the washed surfaces but also of other surfaces in the room and of the air.

\section{Introduction}

Household bleach is largely a sodium hypochlorite ( $\mathrm{NaOCl}$ ) solution commonly formed by electrochemical oxidation of chloride in basic solutions. With a pKa of 7.4 , hypochlorous acid $(\mathrm{HOCl})$ dissociates to $\mathrm{ClO}^{-}$in sufficiently basic solutions, i.e. as in commercial bleach solutions which have a $\mathrm{pH}$ significantly higher than the $\mathrm{HOCl} \mathrm{pKa}$. When chloride is present under sufficiently acidic or dry conditions, the aqueous-phase equilibrium between $\mathrm{Cl}_{2}, \mathrm{HCl}$ and $\mathrm{HOCl} / \mathrm{OCl}^{-}$shifts from $\mathrm{HOCl} / \mathrm{OCl}^{-}$to $\mathrm{Cl}_{2}$ :

$$
2 \mathrm{H}_{3} \mathrm{O}^{+}+\mathrm{ClO}^{-}+\mathrm{Cl}^{-} \leftrightharpoons \mathrm{Cl}_{2}+3 \mathrm{H}_{2} \mathrm{O}
$$

This article is protected by copyright. All rights reserved. 
Please refer to Figure 1 for a detailed schematic of the reaction mechanisms prevalent in this work.

Active chlorine in the form of $\mathrm{HOCl}$ is a good oxidizing agent and is used widely as an antimicrobial agent in water systems, both for sanitizing drinking water and swimming pools. As well, it is used in household and commercial settings as a cleaning agent of both surfaces and clothes. $\mathrm{HOCl}$ exhibits a broad disinfecting ability given its reactivity with a number of types of biomolecules, leading to protein denaturation, radical production, and lipid peroxidation. ${ }^{1,2}$ Being a neutral species, it can more easily cross through cell membranes than its anionic counterpart, $\mathrm{ClO}^{-}$. Specifically, $\mathrm{HOCl}$ is a good oxidizing agent of thiol groups leading to protein modification. ${ }^{3}$ It can also react with nitrogenated biomolecules, such as nitrogen-containing amino acids within DNA and RNA. ${ }^{3,4}$ Finally, $\mathrm{HOCl}$ is known to add across carbon-carbon double bonds forming chlorohydrins. ${ }^{2}$ Thus, it can modify the properties of unsaturated lipid molecules, potentially affecting membrane properties and leading to oxidative stress and peroxidation via the formation of singlet molecular oxygen. ${ }^{5,6} \mathrm{HOCl}$ is formed endogenously in the body by the myeloperoxidase enzyme present within classes of white blood cells. ${ }^{7}$ It is naturally released as an infection control agent given its antimicrobial properties.

From the photochemical perspective, small chlorinated molecules such as $\mathrm{HOCl}$ and $\mathrm{Cl}_{2}$ are well known participants in atmospheric photochemical and multiphase reactions, such as those that occur in the Antarctic Ozone Hole. Reactions of particular importance in that environment include the formation of $\mathrm{Cl}_{2}$ from a heterogeneous reaction occurring on polar stratospheric cloud materials between $\mathrm{HOCl}$ and $\mathrm{HCl}$ :

$$
\mathrm{HOCl}+\mathrm{HCl} \rightarrow \mathrm{Cl}_{2}+\mathrm{H}_{2} \mathrm{O}
$$

This reaction proceeds extremely rapidly with uptake coefficients approaching unity on cold ice surfaces. $^{8}$ The aqueous counterpart of reaction (2), i.e. reaction (1), is reasonably facile with a liquidphase rate constant of $4 \times 10^{4} \mathrm{M}^{-2} \mathrm{~s}^{-1}$ in the forward direction. ${ }^{2}$ Once liberated, $\mathrm{Cl}_{2}$ is sufficiently volatile that it is released to the gas phase where it can be readily photolyzed with near ultraviolet/visible light to form atomic chlorine that drives important ozone-destroying catalytic cycles. Chemistry of a similar nature also occurs in the tropospheric marine boundary layer. ${ }^{9}$

This article is protected by copyright. All rights reserved. 
The role of chlorine-containing substances on the quality of indoor air has been investigated to only a small degree. One study has reported halogenated volatile organic compounds (VOCs) such as chloroform and carbon tetrachloride present in the headspace of bleach solutions and indoor settings, possibly arising from $\mathrm{HOCl}$ reacting with organic surfactant compounds added to bleach. ${ }^{10 \text {, }}$

${ }^{11}$ Similarly, it was found that chloroform can be released from the use of bleach in washing machines. ${ }^{12}$ Additionally, emissions of chloroform have also been documented from other indoor water use activities, such as showering. ${ }^{13,14}$ The general topic of the potential impacts arising from indoor cleaning agents has been discussed in a review which summarizes a number of reported incidents of inappropriate simultaneous use of bleach with ammoniated cleaners. ${ }^{15}$ This chemistry produces chloramines which are themselves disinfecting agents but can also have negative effects on human health. As well, there have been incidents in which acidity drives Reaction (1) forward, releasing chlorine gas. ${ }^{15}$ Finally, other chlorinated species, in particular chlorine dioxide, have been used for indoor disinfection ${ }^{16}$ with OClO exhibiting surface uptake capability. ${ }^{17}$

Given the small number of bleach-related indoor air studies, this paper addresses the impacts arising from the use of bleach as a surface-washing agent. We ask the following questions: What mixing ratios of reactive chlorinated gases such as $\mathrm{Cl}_{2}$ and $\mathrm{HOCl}$ arise when bleach is used indoors? Is only the gas-phase composition of a room affected or are there also impacts on the suspended particulate matter? Is there evidence for uptake of these gas-phase molecules by indoor surfaces? What photochemistry will result from the bleach emissions? What other species are released to the indoor environment when washing with bleach? Our goals are not to quantitatively assess the variability of emissions by surveying a wide range of bleach sources, or the variability of emissions that might arise from one bleach supplier. Instead, the focus is on identifying for the first time the suite of molecules that may be released to the indoor environment and to assess the behavior that they exhibit once released. One particular issue is the formation of oxidants, such as the $\mathrm{OH}$ and $\mathrm{Cl}$ radicals, that might arise through photolysis of chlorinated compounds. These radicals have the potential to increase the oxidizing capacity of indoor air and shorten the lifetime of VOCs.

\section{Methods}

\section{Experimental}

Experiments were conducted in a chemistry laboratory with continuous linoleum flooring, i.e. there are no seams or joints other than where the flooring meets the wall. The concrete ceiling and cinder block walls are painted with a gloss paint. The room has dimensions of $12.2 \mathrm{~m}$ long by

This article is protected by copyright. All rights reserved. 
$6.7 \mathrm{~m}$ wide by $3.8 \mathrm{~m}$ high, and contains scientific equipment as well as cabinets and benches. We estimate the free air volume is $292 \pm 15 \mathrm{~m}^{3}$, where the uncertainty is associated largely with uncertainties in the volumes of the objects in the room. Lighting is provided by four large windows (each $2.9 \mathrm{~m}^{2}$ ) and fluorescent lights. In the middle of the room, the lights levels were roughly 0.7 $\mathrm{W} / \mathrm{m}^{2}$ as measured with a spectral radiometer from 300 to $800 \mathrm{~nm}$ when the lights were on and the windows uncovered. Roughly half the flux came from the windows and half from the fluorescent lights. Building air is not recirculated. It enters the room through vents in the ceiling having first been chilled and filtered, and it mostly exits through two fume hoods in the room. The temperature in the room was typically between 23 and $26^{\circ} \mathrm{C}$ and the relative humidity was less than $60 \%$.

The air exchange rate was measured by allowing dry ice to sublime at a number of locations around the room until the $\mathrm{CO}_{2}$ mixing ratio reached roughly 1000 ppm levels. Fans were deployed in the room to ensure homogeneous mixing of air. The remaining dry ice was then quickly removed from the room and the $\mathrm{CO}_{2}$ level was monitored (Thermo Model 410i) as a function of time as it declined to background levels, without any human participants in the room. Measurements were conducted four times in total across three different days. The $\mathrm{CO}_{2}$ decay rates were highly reproducible across these replicates (Table 1 ), indicating minimal fluctuations in the building air exchange rate.

Experiments were conducted by washing the floor with a bleach solution prepared according to manufacturer recommendations, i.e. a $97 \%$ dilution of the stock solution using MilliQ water in a plastic bucket. Mopping (with a commercial mop) roughly half of the floor area $\left(37 \pm 5 \mathrm{~m}^{2}\right)$ was conducted rapidly, on the order of a minute or so. The height of the solution in the bucket was measured, yielding an average value of $200 \pm 44 \mathrm{~mL}$ of solution applied in each experiment. Floor washing was conducted with at most three people in the room, and once the washing was complete the participants left the lab for roughly 30 to 45 minutes leaving the on-line instruments monitoring.

On-line measurements were conducted using instruments placed within the laboratory. A chemical ionization mass spectrometer (CIMS, Aerodyne Inc.), consisting of an iodide reagent ion source and a time-of-flight mass spectrometer (mass resolution of roughly $3000\left(\mathrm{Th} \mathrm{Th}^{-1}\right)$ ) sampled room air without a sample line at a rate of $300 \mathrm{sccm}$ and at a height of $1 \mathrm{~m}$ from the floor. ${ }^{18}$ This sample flow was diluted with $1700 \mathrm{sccm}$ of nitrogen flow to ensure that the iodide reagent ion was always in excess (i.e. the average decrease in iodide reagent ion was $3 \%$ during a typical mopping experiment). The iodide ion readily clusters with a large range of gas-phase species (X), including a

This article is protected by copyright. All rights reserved. 
variety of chlorinated compounds, detecting them as $\mathrm{I}^{-} \cdot \mathrm{X}$ adducts. ${ }^{19,20}$ Positive identification of chlorinated gases is made using both high-resolution mass fitting of the mass spectra peaks and from the expected isotopic composition of the gases arising from the ${ }^{35} \mathrm{Cl}$ and ${ }^{37} \mathrm{Cl}$ isotopes.

Signals of $\mathrm{Cl}_{2}$ were calibrated in a standard manner by supplying known amounts of gas from a glass bulb of known volume containing a dilute mixture of $\mathrm{Cl}_{2}$ in nitrogen. The bulb was prepared by sequential dilution of a small quantity of pure $\mathrm{Cl}_{2}$ using a capacitance monometer (MKS Inc.) mounted on a vacuum manifold to measure the dilution ratios.

$\mathrm{HOCl}$ is not commercially available as a gas. As a result, $\mathrm{HOCl}$ mixing ratios were calibrated by converting $\mathrm{HOCl}$ to $\mathrm{Cl}_{2}$ according to a modified procedure described previously. ${ }^{21}$ In particular, the $\mathrm{HOCl}$ and $\mathrm{Cl}_{2}$ signals were observed when a $25-30 \mathrm{sccm}$ nitrogen flow from a $1 \%$ by weight solution of $\mathrm{NaOCl}$, buffered to $\mathrm{pH} 7.0$ using a phosphate buffer, passes over a $10 \%$ by weight solution of $\mathrm{NaCl}$ containing $1 \% \mathrm{HCl}$ and held at $0{ }^{\circ} \mathrm{C}$. From the decrease in $\mathrm{HOCl}$ signal and the associated increase in $\mathrm{Cl}_{2}$ signal when passing over the chloride solution, the relative sensitivities of the CIMS to the two species can be determined. Using this information, as well as the $\mathrm{Cl}_{2}$ instrumental sensitivity determined as described above, the $\mathrm{HOCl}$ sensitivity is assessed. We estimate absolute uncertainties in the reported $\mathrm{Cl}_{2}$ mixing ratios to be on the order of $\pm 30 \%$, arising from the uncertainties in the $\mathrm{Cl}_{2}$ mixing ratio in the glass bulb and the calibration. The uncertainty in the $\mathrm{HOCl}$ mixing ratios is considerably higher than that for $\mathrm{Cl}_{2}$, on the order of a factor two, i.e. $\pm 50 \%$. In addition, the mixing ratios of $\mathrm{HOCl}$ reported in the paper are likely lower limits to the true values given that our calibration procedure assumes unity conversion of $\mathrm{HOCl}$ to $\mathrm{Cl}_{2}$. Enhanced relative humidity had minor effects on the instrumental sensitivity, and the detection limits for $\mathrm{Cl}_{2}$ and $\mathrm{HOCl}$ were 7 and 53 pptv respectively (at three sigma of the background).

Aerosol composition was monitored on-line by an Aerodyne aerosol mass spectrometer (AMS) with a compact time-of-flight mass spectrometer (C-ToF-AMS). Room air was sampled at a flow rate of $90 \mathrm{sccm}$ with no sample line attached and with the inlet at $1.3 \mathrm{~m}$ from the floor. The AMS has been reviewed elsewhere. ${ }^{22}$ It operates using electron impact ionization of vaporized species that arise after a particle beam under vacuum impacts a heated vaporizer. The ions are then extracted into a time-of-flight mass spectrometer. The AMS is largely sensitive to non-refractory particles below one micron in diameter. The instrument is calibrated using known quantities of nitrate aerosol, and the mass loadings of other species are then assessed using relative ionization efficiencies which, for this work, are taken to be: 1.2 for sulfate, 1.4 for organics, and 1.3 for chlorine. $^{22}$

This article is protected by copyright. All rights reserved. 
Gas-phase ozone $\left(\mathrm{O}_{3}\right)$ was measured using a Thermo monitor (Model 49i), and sub-micron aerosol size distributions were measured with a scanning mobility particle sizing (SMPS) system from TSI Inc. which included a model 3080 DMA and model 3025 CPC.

The hypochlorite composition of the commercial bleach solution was measured to be $8.7 \pm$ $0.1 \%$ (by mass) by reacting the solution with excess $\mathrm{H}_{2} \mathrm{O}_{2}$ and measuring the volume of $\mathrm{O}_{2}$ gas released:

$$
\mathrm{NaOCl}+\mathrm{H}_{2} \mathrm{O}_{2} \rightarrow \mathrm{O}_{2}+\mathrm{NaCl}+\mathrm{H}_{2} \mathrm{O}
$$

\section{Modeling}

The modeling was carried out using the Indoor Chemical Model (INDCM) as described previously. ${ }^{23,24}$ The zero-dimensional box-model uses a detailed chemical mechanism based on the Master Chemical Mechanism (MCM) ${ }^{25,26}$ which is adapted for use indoors through the inclusion of terms that represent surface deposition, photolysis via attenuated light from outdoors and/or indoor lighting, exchange with outdoors and indoor emissions.

Although the MCM contains chemical degradation schemes for a number of halogenated hydrocarbons and considers reaction of the $\mathrm{Cl}$ radical with a range of alkanes, it does not contain comprehensive chlorine chemistry. Therefore, a recently developed module for studying chlorine chemistry at a coastal site in Hong Kong and designed for use in the MCM by Xue et al. ${ }^{27}$ was added to the INDCM to address this gap. The new mechanism contains 205 reactions that represents the reactions of a range of VOCs with the $\mathrm{Cl}$ radical, as well as inorganic chemistry of both $\mathrm{Cl}$ and its precursors.

The model was modified to represent the dimensions of the laboratory, providing a surface area to volume ratio of $\sim 1.0 \mathrm{~m}^{-1}$ to drive deposition of gases in the model. The observed air exchange rate of $12.74 \mathrm{~h}^{-1}$ was used and photolysis rates were calculated for indoor lighting according to the method described by Nazaroff and Cass. ${ }^{28}$ The wavelength dependent quantum yields for the new chlorinated species were taken from the latest IUPAC evaluation. ${ }^{29}$ Outdoor light was assumed to be attenuated by $97 \%$ in the UV and $90 \%$ in the visible when compared to outdoors, ${ }^{23}$ though this assumption was tested as described later.

Outdoor VOC concentrations in the model were initialised according to Sarwar et al., ${ }^{30}$ whilst $\mathrm{NO}, \mathrm{NO}_{2}, \mathrm{SO}_{2}$ and $\mathrm{CO}$ were taken from annual mean values from downtown or west Toronto ${ }^{31}$ and were set to $2.7,13.5,0.6$ and $250 \mathrm{ppb}$ respectively. Given the high air exchange rate, indoor

This article is protected by copyright. All rights reserved. 
steady-state $\mathrm{NO}$ and $\mathrm{NO}_{2}$ mixing ratios are $\sim 0.4$ and $14 \mathrm{ppb}$ respectively (at the high air exchange rate, indoor concentrations approximate those outdoors in the absence of indoor emissions, plus some $\mathrm{NO}$ is converted to $\mathrm{NO}_{2}$ through reaction with $\mathrm{O}_{3}$ ). Indoor ozone mixing ratios varied between $30-50 \mathrm{ppb}$ over the course of the experiments and these measured mixing ratios were used to guide the model runs.

The new chlorine mechanism considers uptake of four species $\left(\mathrm{NO}_{3}, \mathrm{~N}_{2} \mathrm{O}_{5}, \mathrm{ClONO}_{2}\right.$ and $\left.\mathrm{HOCl}\right)$ onto aerosol surfaces. The uptake coefficients were assumed to be $4 \times 10^{-3}$ for $\mathrm{NO}_{3}$ and $1 \times 10^{-2}$ for the other three species. ${ }^{27}$ During the experiments, SMPS data indicated the average value of aerosol surface area was $1.3 \times 10^{-4} \mathrm{~cm}^{2} / \mathrm{cm}^{3}$.

The amount of bleach solution used per mopping event and its concentration enabled an emission rate to be calculated. In particular, it was estimated that $\sim 7 \times 10^{-3}$ moles of $\mathrm{HOCl}$ were emitted into the room over 1 minute of mopping. Given the room volume, the emission rate of $\mathrm{HOCl}$ was calculated to be $\sim 9.6 \mathrm{ppb} /\left(\mathrm{cm}^{3} \mathrm{~s}\right)$. Although the mopping lasted for only 1 minute, the emission into the room likely lasted longer, continuing as the bleach solution evaporates. The emission rate was therefore varied in the model to apply the relevant quantity of $\mathrm{HOCl}$ over time periods varying from 1-5 minutes. It was found that the shapes of the measured peaks were best reproduced when the emission was assumed to occur over 5 minutes. Therefore, the emission rate was set to $\sim 1.92$ $\mathrm{ppb} / \mathrm{cm}^{3} / \mathrm{s}$ over 5 minutes.

As described below, $\mathrm{Cl}_{2}$ was detected in the bleach solution headspace indicating it was present as an impurity. A direct emission of $\mathrm{Cl}_{2}$ into the laboratory was therefore assumed. The sensitivity of the model was tested and the $\mathrm{Cl}_{2}$ direct emission was found to be optimal at $5 \%$ of $\mathrm{HOCl}$. Also, there are unlikely to be chemical or physical losses for $\mathrm{Cl}_{2}$ within the room, given it appears (see below) to be removed at the rapid air exchange rate. We therefore assumed that deposition of $\mathrm{Cl}_{2}$ to surfaces was negligible.

\section{Experimental Results and Discussion}

Figure $2 \mathrm{~A}$ presents a typical mass spectrum obtained from the room air immediately after floor mopping, where mass spectral signals are normalized to reagent ion intensity and represent the difference in signal between when bleach is present and prior to its application. Figure $2 \mathrm{~B}$ is a mass spectrum taken by passing a small flow of air through the bleach solution in a glass bubbler. Clearly identifiable peaks arise from iodide clustering with $\mathrm{ClO}, \mathrm{Cl}, \mathrm{HOCl}, \mathrm{ClNO}_{2}, \mathrm{NHCl}_{2}$ and $\mathrm{NCl}_{3}$. High mass resolution peak fitting has established the elemental composition of each ion (see SI

This article is protected by copyright. All rights reserved. 
Figure 1 and SI Table 1). Confirmation of molecular assignments comes from the chlorine isotopic abundances (see SI Table 2). We note that the largest peak in the spectrum aside from the reagent ion (not shown) is $\mathrm{I}^{\mathrm{I}} \cdot \mathrm{Cl}$ which could arise from fragmentation of iodide clusters with chlorinated molecules. Although this needs to be confirmed, we believe that the iodide cluster with $\mathrm{ClO}$ may also arise from fragmentation of larger species, given that it is unlikely that a reactive radical would be measured at comparable signal intensities as other non-radical species, such as $\mathrm{NHCl}_{2}$. However, we can not rule out the presence of $\mathrm{ClO}$ radical.

In Figure 3 temporal data are plotted from a typical set of mopping experiments. In Figure $3 \mathrm{~A}$, the data for $\mathrm{Cl}_{2}$ and $\mathrm{HOCl}$ are represented by their reagent-ion-normalized signals and also by their mixing ratios in the room. As well, the normalized signal for $\mathrm{ClO}$ and $\mathrm{Cl}_{2} \mathrm{O}$ (multiplied by 100) are included. In each case, the signal is that due to the strongest isotopic peak in the spectrum. Figure $3 \mathrm{~B}$ shows the reagent-ion-normalized signals of the mixed chlorine-nitrogen species: $\mathrm{CINO}_{2}$, $\mathrm{NCl}_{3}$ and $\mathrm{NHCl}_{2}$.

At the start of each day of mopping experiments, a control experiment was conducted (at 11:19 am for the data in Figure 3), where the floor was mopped with MilliQ water and no bleach solution was applied. No large signals arise from this activity. Four subsequent bleach mopping experiments are shown in Figure 3, starting at roughly 11:50 AM, 12:30 PM, 1:15 PM and 2:00 PM. In each case, the chlorinated signals rise and then decay away as the air is flushed from the room.

Two of the most prominent peaks in the mopping experiment arise from $\mathrm{Cl}_{2}$ and $\mathrm{HOCl}$ (Figure 2A). Interestingly, the $\mathrm{HOCl}$ signal is largely absent in the headspace spectrum (Figure 2B). These values are compared graphically in Figure 4 where we have referenced each maximum signal to that due to $\mathrm{Cl}_{2}$, for both the mopping and headspace data. It is seen that the mopping $\mathrm{HOCl}$ data are orders of magnitude higher than the headspace data, likely due to solution acidity and dilution effects. In particular, the $\mathrm{pH}$ of the diluted bleach solution was measured to be 11 , i.e. $\mathrm{HOCl}$ will be fully dissociated into the $\mathrm{ClO}^{-}$form and thus unlikely to volatilize. By contrast, we hypothesize that uptake of $\mathrm{CO}_{2}$ from the air will acidify the solution after mopping, shifting the $\mathrm{HOCl} / \mathrm{ClO}^{-}$acid-base equilibrium over to the $\mathrm{HOCl}$ form which will be much more volatile (see Figure 1):

$$
\mathrm{H}_{3} \mathrm{O}^{+}+\mathrm{ClO}^{-} \leftrightharpoons \mathrm{HOCl}+\mathrm{H}_{2} \mathrm{O}
$$

This article is protected by copyright. All rights reserved. 
It is also possible that acidic species are present on the floor surfaces that affect the equilibrium. Evaporation of water from the drying bleach solution will also shift the equilibrium in Reaction (4) to the right. Finally, we note that the species $\mathrm{Cl}_{2} \mathrm{O}$ was observed in both the mopping and headspace spectra with a maximum normalized signal of roughly $3 \times 10^{-3} \cdot \mathrm{Cl}_{2} \mathrm{O}$ is the anhydride of $\mathrm{HOCl}$ (see Figure 1):

$$
\mathrm{HOCl}+\mathrm{HOCl} \leftrightharpoons \mathrm{Cl}_{2} \mathrm{O}+\mathrm{H}_{2} \mathrm{O}
$$

While the presence of $\mathrm{Cl}_{2}$ and $\mathrm{HOCl}\left(\right.$ and $\mathrm{Cl}_{2} \mathrm{O}$ ) arising from a bleach solution is expected based on the chemistry presented in the Introduction, the large signals from a number of the other observed species is unexpected. $\mathrm{CINO}_{2}$ is a well known atmospheric constituent formed by a multiphase reaction between gaseous $\mathrm{N}_{2} \mathrm{O}_{5}$ and chloride-containing surfaces, such as sorbed $\mathrm{HCl}$, or with $\mathrm{NaCl}$ (see Figure 1$)^{32}$

$$
\mathrm{N}_{2} \mathrm{O}_{5}+\mathrm{HCl} / \mathrm{NaCl} \rightarrow \mathrm{ClNO}_{2}+\mathrm{HNO}_{3} / \mathrm{NaNO}_{3}
$$

We note that $\mathrm{CINO}_{2}$ was also observed when we sampled the vapour directly from a bleach solution (see Figure 4) but, when accounting for experimental uncertainties and referencing to $\mathrm{Cl}_{2}$, the observed levels were not significantly higher after mopping. (Note that the comparison in Figure 4 is for reagent-ion-normalized signals allowing comparison between data sets measured under different conditions.) This leaves open the question that some $\mathrm{ClNO}_{2}$ arose through reaction (6) occurring on surfaces in the room, where $\mathrm{N}_{2} \mathrm{O}_{5}$ would be formed by $\mathrm{NO}_{3}$ reacting with $\mathrm{NO}_{2}, \mathrm{NO}_{3}$ being generated by the reaction of outdoor $\mathrm{NO}_{2}$ with $\mathrm{O}_{3}$. We note that this chemistry should occur readily in dark and dimly lit surroundings, such as indoors. $\mathrm{ClNO}_{2}$ is not readily calibrated using instrumentation in our lab but we note that the normalized signal levels were similar to those for both $\mathrm{HOCl}$ and $\mathrm{Cl}_{2}$. This implies that the indoor mixing ratios of $\mathrm{CINO}_{2}$ could potentially significantly exceed those in the outdoor environment, that are normally in the sub-ppbv range. ${ }^{9}$

Also observed in both the room air after washing and in the bleach solution headspace were two chloramines, $\mathrm{NHCl}_{2}$ and $\mathrm{NCl}_{3}$. These are known products from the reaction of $\mathrm{HOCl}$ with ammonia, as occurs in swimming pools that use chlorine as a disinfectant. Comparing the mopping

This article is protected by copyright. All rights reserved. 
and headspace conditions, the ratio of $\mathrm{NCl}_{3}$ to $\mathrm{NHCl}_{2}$ decreased in the mopping condition. It is difficult to establish why this ratio changes, perhaps arising from loss of $\mathrm{HOCl}$ through volatilization to the room after mopping (although loss of water would expect to push the equilibrium in the reverse direction) (see Figure 1):

$$
\mathrm{HOCl}+\mathrm{NHCl}_{2} \leftrightharpoons \mathrm{NCl}_{3}+\mathrm{H}_{2} \mathrm{O}
$$

In Figure 3, it is seen that all the species decay rapidly after the mopping is complete. The first-order decay rate constants of the different CIMS signals are presented in Table 1, along with the mean decay for $\mathrm{CO}_{2}$ from independent experiments. The latter value is $(3.54 \pm 0.08) \times 10^{-3} \mathrm{~s}^{-1}$ which is very rapid for an indoor setting but arises in a chemistry laboratory that requires fast air turnover. The decay constant is derived by fitting an exponential function to the decaying portion of the gas signal profile.

We note that within experimental uncertainties, the $\mathrm{Cl}_{2}$ and $\mathrm{NCl}_{3}$ signals decayed at the air exchange rate (see Figure 5, for $\mathrm{Cl}_{2}$ ). This implies that on this timescale, these species do not undergo significant chemistry once liberated into the gas phase. In particular, the decay rates were the same regardless of whether the experiment was conducted with the lights on or off, or with the windows covered, indicating that there is no photochemical loss on the air exchange timescale. On the other hand, $\mathrm{CINO}_{2}$ and $\mathrm{NHCl}_{2}$ decayed somewhat more slowly than did $\mathrm{CO}_{2}$, perhaps indicative of slow desorption from surfaces in the lab. By contrast, the $\mathrm{HOCl}$ signals decayed at, on average, 1.4 times the room air exchange rate, again regardless of whether the room was illuminated or not. As well, the maximum mixing ratio reached by $\mathrm{HOCl}$ became progressively higher with subsequent moppings during the day (e.g. see Figure 3). We interpret this set of observations as indicative of increasing amounts of $\mathrm{HOCl}$ being liberated from the floor after each mopping event as well as, potentially, from different rates of multiphase chemistry occurring between gaseous $\mathrm{HOCl}$ and other surfaces present in the room. At this point we cannot determine whether the uptake from the gas phase leading to the rapid decay is via inorganic processes, e.g. $\mathrm{HOCl}$ reacting with surficial chloride, or with organic materials, or via redox reactions involving $\mathrm{HOCl}^{33}$ In either case, the increasing levels of $\mathrm{HOCl}$ in the room after subsequent floor washings likely arise because the $\mathrm{HOCl}$ is consuming reactive materials on the floor and/or other surfaces, leaving less available for subsequent reactions. Additionally, we note that the rate of $\mathrm{HOCl}$ surface chemistry occurs on the

This article is protected by copyright. All rights reserved. 
same order of magnitude as indoor ozone surface chemistry (typical decay rates of ozone due to removal by indoor surfaces range from $\left.(0.22-2.0) \times 10^{-3} \mathrm{~s}^{-1}\right) .^{34}$

In the absence of surface reactions, the areas under the curves in Figure $3 \mathrm{~A}$ are measures of the amount of $\mathrm{Cl}_{2}$ and $\mathrm{HOCl}$ released to the room. Those integrated values are in Table 2 in units of ppbv minutes. A large amount of variability exists in the $\mathrm{HOCl}$ signal within a day (as described above) and also between days. $\mathrm{Cl}_{2}$ shows such variability between days as well, although not to the same degree as $\mathrm{HOCl}$. This observation is deserving of additional study to systematically determine whether the changing nature of the surfaces being mopped was giving rise to different values in the gas phase. The active chlorine level of the undiluted bleach source used in this work was determined to be stable to the $0.2 \%$ (by mass) level over a period of 30 days, i.e. the variability in the amounts of $\mathrm{HOCl}$ released from one day to the next does not arise from changing strength of the bleach solution.

Figure $3 \mathrm{C}$ shows the aerosol particulate mass loadings observed in the room via aerosol mass spectrometry. As expected, there is no effect on the levels of organic and sulfate aerosol components that arise by mopping but, interestingly, the aerosol chlorine loading responded to each mopping experiment. As mentioned above, the amount of particulate chlorine mass plotted in Figure $3 \mathrm{C}$ is dependent on the relative ionization efficiency employed in the analysis and, for this reason, should be viewed with some caution given that we do know the form of the particulate chlorine. Aerosol chlorine may arise from either unreactive partitioning to the room particulates or else via reactive uptake of gas-phase chlorinated species. We note that there is a general increase in the levels of particulate chlorine with increasing total particulate mass loadings (see Figure SI-2) but this relationship could arise from either reactive or non-reactive partitioning processes. It is striking that the levels of particulate chlorine rise at comparable timescales to those of the gas-phase chlorine signals, indicating uptake on a timescale of minutes or less. They decay (see Table 1) at rates just slightly lower than those for $\mathrm{CO}_{2}$.

\section{Implications for Indoor Chemistry}

The implications of these observations for indoor chemistry are assessed using the modeling approach described above, with a focus on the data in Figure 3. When all the $\mathrm{HOCl}$ in the bleach solution was emitted into the room, the model predicted a gas-phase mixing ratio of $\mathrm{HOCl}$ of $\sim 450$ $\mathrm{ppb}$, in excess of the measured values. Further, the predicted mixing ratios of $\mathrm{HOCl}$ did not increase with each application as shown by the measurements. As described above, this observation

This article is protected by copyright. All rights reserved. 
indicated that a significant amount of the $\mathrm{HOCl}$ was lost on the surface of the floor during mopping and also, that the efficiency of this surface loss decreased with time. Therefore, the model was run with varying amounts of $\mathrm{HOCl}$ assumed to stick to surfaces, with this proportion varying over time in line with the surface becoming saturated. The experimental data were used to tune the model in this respect and the results are discussed below.

To determine the optimal combination of model input parameters, each non-zero experimental data point was paired with the equivalent model result for $\mathrm{Cl}_{2}$ and $\mathrm{HOCl}$ and the root mean square difference determined for all points in each peak. This value was then normalised to the averaged experimental mixing ratio during each of the peaks so that differences between experiment and model for the higher mixing ratio peaks didn't bias the discrepancy between model and measurements. The results presented are those for which the overall root mean square differences are minimised.

The best results were found for the following conditions when it was assumed that the amount of $\mathrm{HOCl}$ lost to the surface was $74 \%, 60 \%, 52 \%$ and $40 \%$ for peaks $1-4$ respectively, with a deposition velocity for $\mathrm{HOCl}$ to surfaces in the room of $0.035 \mathrm{~cm} \mathrm{~s}^{-1}$ (see Figure 6). This latter value is very similar to that observed for $\mathrm{O}_{3}$ deposition indoors. ${ }^{24}$

The model can also be used to investigate the concentrations of radical species $\mathrm{O} \mathrm{OH}, \mathrm{Cl}$ and $\mathrm{ClO}$ ) formed in its chlorine mechanism. The photolysis of $\mathrm{HOCl}$ produces $\mathrm{OH}$ and $\mathrm{Cl}$, leading to other radicals following reactions with VOCs (in the case of $\mathrm{OH}$ to produce $\mathrm{HO}_{2}$ and $\mathrm{RO}_{2}$ ) and with $\mathrm{O}_{3}$ (in the case of $\mathrm{Cl}$ to form $\mathrm{ClO}$ ). Figure 7 shows the modeled concentrations of $\mathrm{OH}, \mathrm{Cl}$ and $\mathrm{ClO}$. Note that in order to investigate the impact of light on the radical concentrations, these figures are shown with four different lighting conditions:

1. $3 \%$ and $10 \%$ of outdoor UV and visible light respectively plus indoor lighting

2. $1.5 \%$ and $5 \%$ of outdoor UV and visible light respectively plus indoor lighting

3. Just indoor lighting

4. Dark

The model runs illustrate that mopping events exert a prominent impact on the indoor radical concentrations which vary significantly with the intensity and type of light. Radical mixing ratios rise from their background levels immediately following the onset of mopping events. With the highest intensity of light assumed (case 1), the $\mathrm{OH}$ radical concentration can reach $2.0 \times 10^{6}$ molec $\mathrm{cm}^{-3}$ which is equivalent or higher than typical outdoor values, and very much higher than

This article is protected by copyright. All rights reserved. 
typical indoor levels. Even in the absence of any outdoor light, mopping events can lead to appreciable concentrations of radicals. Interestingly, mopping events in the dark can result in a slight decrease in the $\mathrm{OH}$ radical concentration.

We used the INDCM to investigate the controlling rates of reaction for $\mathrm{HOCl}$ and $\mathrm{Cl}_{2}$ removal. For $\mathrm{Cl}_{2}$, at least $98 \%$ is removed through air exchange with the remaining up to $2 \%$ via photolysis. This prediction is consistent with the data in Figure 5. For $\mathrm{HOCl}$, around $88 \%$ is removed through air exchange with around $9 \%$ via dry deposition and $3 \%$ via removal on aerosol surfaces.

Finally, the loss rates of different $\mathrm{VOCs}$ via $\mathrm{OH}$ or $\mathrm{Cl}$ were compared to determine which oxidants are most important under these conditions. For isoprene, loss through reaction with $\mathrm{OH}$ was $\sim 4$ times faster than for $\mathrm{Cl}$, 2 times faster for propene and 1.3 times faster for $\mathrm{CH}_{4}$. However, for $n$-butane, loss via reaction with $\mathrm{Cl}$ was $~ 3$ times faster than loss via reaction with $\mathrm{OH}$ under experimental conditions.

\section{Conclusions}

Elevated levels of gas-phase $\mathrm{Cl}_{2}$ and $\mathrm{HOCl}$ arise after floor washing with a commercial bleach solution. We note that the maximum mixing ratios reported were attained in a room with an extremely fast air exchange rate $\left(12.7 \mathrm{~h}^{-1}\right)$, one to two orders of magnitude higher than that in other indoor environments, such as schools, offices and restaurants where bleach flooring washing may be employed. Proportionally higher mixing ratios than those observed will arise in indoor spaces with more commonly encountered air exchange rates. The elevated $\mathrm{Cl}_{2}$ and $\mathrm{HOCl}$ levels lead to enhanced concentrations of reactive free radicals, $\mathrm{OH}, \mathrm{Cl}$ and $\mathrm{ClO}$, that will shorten the lifetimes of gas-phase organics with subsequent environmental effects, such as enhanced rates of secondary organic aerosol formation. The observations of elevated levels of gas-phase $\mathrm{CINO}_{2}, \mathrm{NHCl}_{2}$ and $\mathrm{NCl}_{3}$, as well as particulate chlorine, were unexpected. Beyond the scope of this work, it is important to study their formation routes and potential impacts.

Bleach is used commonly as an oxidative disinfectant. It is intriguing that its impacts appear not to be restricted to the surfaces to which the cleaning solution is applied. In addition, the uptake of $\mathrm{HOCl}$ onto other room surfaces has the potential to react with organics and amines present on those surfaces. We note that these potential surface reactions may be even more significant in a typical indoor environment where the surface-to-volume ratios are higher than the estimated

This article is protected by copyright. All rights reserved. 
surface-to-volume ratio for the room employed in the current study $\left(\sim 1.0 \mathrm{~m}^{-1}\right)$. Subsequent $\mathrm{Cl}_{2}$ and $\mathrm{HOCl}$ photochemistry will also significantly increase $\mathrm{Cl}$ and $\mathrm{OH}$ radical concentrations, enhancing the oxidizing capacity of the gas-phase. Overall, bleach washing leads to enhanced oxidation rates on both surfaces and in the gas phase.

\section{Acknowledgements}

Financial support from the Alfred P. Sloan Foundation is acknowledged. The help of S.

Abbatt is acknowledged for measuring the active chlorine concentrations in the bleach solution.

\section{References}

1. Panasenko OM, Gorudko IV, Sokolov AV. Hypochlorous acid as a precursor of free radicals in living systems. Biochem.-Moscow. 2013;78(13):1466-1489.

2. Deborde M, von Gunten U. Reactions of chlorine with inorganic and organic compounds during water treatment - Kinetics and mechanisms: A critical review. Water Res. 2008;42(1-2):13-51.

3. Prutz WA. Hypochlorous acid interactions with thiols, nucleotides, DNA, and other biological substrates. Archives of Biochemistry and Biophysics. 1996;332(1):110-120.

4. Suquet $\mathrm{C}$, Warren JJ, Seth $\mathrm{N}$, et al. Comparative study of $\mathrm{HOCl}$-inflicted damage to bacterial DNA ex vivo and within cells. Archives of Biochemistry and Biophysics. 2010;493(2):135-142.

5. Pattison DI, Hawkins CL, Davies MJ. Hypochlorous acid-mediated oxidation of lipid components and antioxidants present in low-density lipoproteins: Absolute rate constants, product analysis, and computational modeling. Chem. Res. Toxicol. 2003;16(4):439-449.

6. Miyamoto $S$, Martinez GR, Rettori $D$, et al. Linoleic acid hydroperoxide reacts with hypochlorous acid, generating peroxyl radical intermediates and singlet molecular oxygen. Proc. Nat. Acad. Sci. U.S.A. $2006 ; 103(2): 293-298$.

7. Pattison DI, Davies MJ, Hawkins CL. Reactions and reactivity of myeloperoxidase-derived oxidants: Differential biological effects of hypochlorous and hypothiocyanous acids. Free Radic. Res. 2012;46(8):975-995.

8. Abbatt JPD, Molina MJ. The heterogeneous reaction of $\mathrm{HOCl}+\mathrm{HCl}-\mathrm{Cl} 2+\mathrm{H} 2 \mathrm{O}$ on ice and nitric acid trihydrate - Reaction probabilites and stratospheric implications. Geophys. Res. Lett. 1992;19(5):461-464.

9. Simpson WR, Brown SS, Saiz-Lopez A, et al. Tropospheric Halogen Chemistry: Sources, Cycling, and Impacts. Chem. Rev. 2015;115(10):4035-4062.

This article is protected by copyright. All rights reserved. 
10. Odabasi M. Halogenated volatile organic compounds from the use of chlorine-bleach-containing household products. Environ. Sci. Technol. 2008;42(5):1445-1451.

11. Odabasi M, Elbir T, Dumanoglu Y, et al. Halogenated volatile organic compounds in chlorinebleach-containing household products and implications for their use. Atmos. Environ. 2014;92:376-383.

12. Shepherd JL, Corsi RL, Kemp J. Chloroform in indoor air and wastewater: The role of residential washing machines. J. Air Waste Manage. Assoc. 1996;46(7):631-642.

13. Giardino NJ, Andelman JB. Characterization of the emissions of trichloroethylene, chloroform, and 1,2-dibromo-3-chloropropane in a full-size, experimental shower. J. Expo. Anal. Environ. Epidemiol. 1996;6(4):413-423.

14. Nuckols JR, Ashley DL, Lyu C, et al. Influence of Tap Water Quality and Household Water Use Activities on Indoor Air and Internal Dose Levels of Trihalomethanes. Environmental Health Perspectives. 2005;113(7):863-870.

15. Nazaroff WW, Weschler CJ. Cleaning products and air fresheners: exposure to primary and secondary air pollutants. Atmos. Environ. 2004;38(18):2841-2865.

16. Gordon G, Rosenblatt AA. Chlorine dioxide: The current state of the art. Ozone-Sci. Eng. 2005;27(3):203-207.

17. Hubbard H, Poppendieck D, Corsi RL. Chlorine Dioxide Reactions with Indoor Materials during Building Disinfection: Surface Uptake. Environ. Sci. Technol. 2009;43(5):1329-1335.

18. Bertram TH, Kimmel JR, Crisp TA, et al. A field-deployable, chemical ionization time-of-flight mass spectrometer. Atmos. Meas. Tech. 2011;4(7):1471-1479.

19. Lee BH, Lopez-Hilfiker FD, Mohr C, et al. An lodide-Adduct High-Resolution Time-of-Flight Chemical-Ionization Mass Spectrometer: Application to Atmospheric Inorganic and Organic Compounds. Environ. Sci. Technol. 2014;48(11):6309-6317.

20. Kercher JP, Riedel TP, Thornton JA. Chlorine activation by N2O5: simultaneous, in situ detection of $\mathrm{CINO} 2$ and $\mathrm{N} 2 \mathrm{O} 5$ by chemical ionization mass spectrometry. Atmos. Meas. Tech. 2009;2(1):193-204.

21. Lawler MJ, Sander R, Carpenter L, et al. $\mathrm{HOCl}$ and $\mathrm{Cl}-2$ observations in marine air. Atmos. Chem. Phys. 2011;11(15):7617-7628.

22. Canagaratna MR, Jayne JT, Jimenez JL, et al. Chemical and microphysical characterization of ambient aerosols with the Aerodyne aerosol mass spectrometer. Mass. Spectrom. Rev. 2007; 26:185-222.

23. Carslaw N. A new detailed chemical model for indoor air pollution. Atmos. Environ. 2007;41:1164-1189.

24. Carslaw N, Mota T, Jenkin ME, et al. A Significant Role for Nitrate and Peroxide Groups on Indoor Secondary Organic Aerosol. Environ. Sci. Technol. 2012;46:9290-9298.

This article is protected by copyright. All rights reserved. 
25. Jenkin ME, Saunders SM, Wagner V, et al. Protocol for the development of the Master Chemical Mechanism, MCM v3 (Part B): tropospheric degradation of aromatic volatile organic compounds. Atmos. Chem. Phys. 2003;3:181-193.

26. Saunders SM, Jenkin ME, Derwent RG, et al. Protocol for the development of the Master Chemical Mechanism, MCM v3 (Part B): tropospheric degradation of aromatic volatile organic compounds. Atmos. Chem. Phys. 2003;3:161-180.

27. Xue LK, Saunders SM, Wang T, et al. Development of a chlorine chemistry module for the Master Chemical Mechanism. Geosci. Model. Dev. 2015;8:3151-3162.

28. Nazaroff WW, Cass GR. Mathematical modeling of chemically reactive pollutants in indoor air. Environ. Sci. Technol. 1986;20:924-934.

29. IUPAC. Evaluated kinetic data at iupac.pole-ether.fr/index.html, date accessed September 2015.

30. Sarwar G, Corsi R, Kimura Y, et al. Hydroxyl radicals in indoor environments. Atmos. Environ. 2002;36:3973-3988.

31. OMECC. Ontario Ministry of the Environment and Climate Change, Air Quality in Ontario 2013 Report, accessed September 2016.

32. Finlayson-Pitts BJ. The tropospheric chemistry of sea salt: A molecular-level view of the chemistry of $\mathrm{NaCl}$ and $\mathrm{NaBr}$. Chem. Rev. 2003;103:4801-4822.

33. Johnson DW, Margerum DW. Non-metal redox kinetics: a reexamination of the mechanism of the reaction between hypochlorite and nitrite ions. Inorganic Chemistry. 1991;30(25):4845-4851.

34. Weschler CJ. Ozone in Indoor Environments: Concentration and Chemistry. Indoor Air. 2000;10(4):269-288.

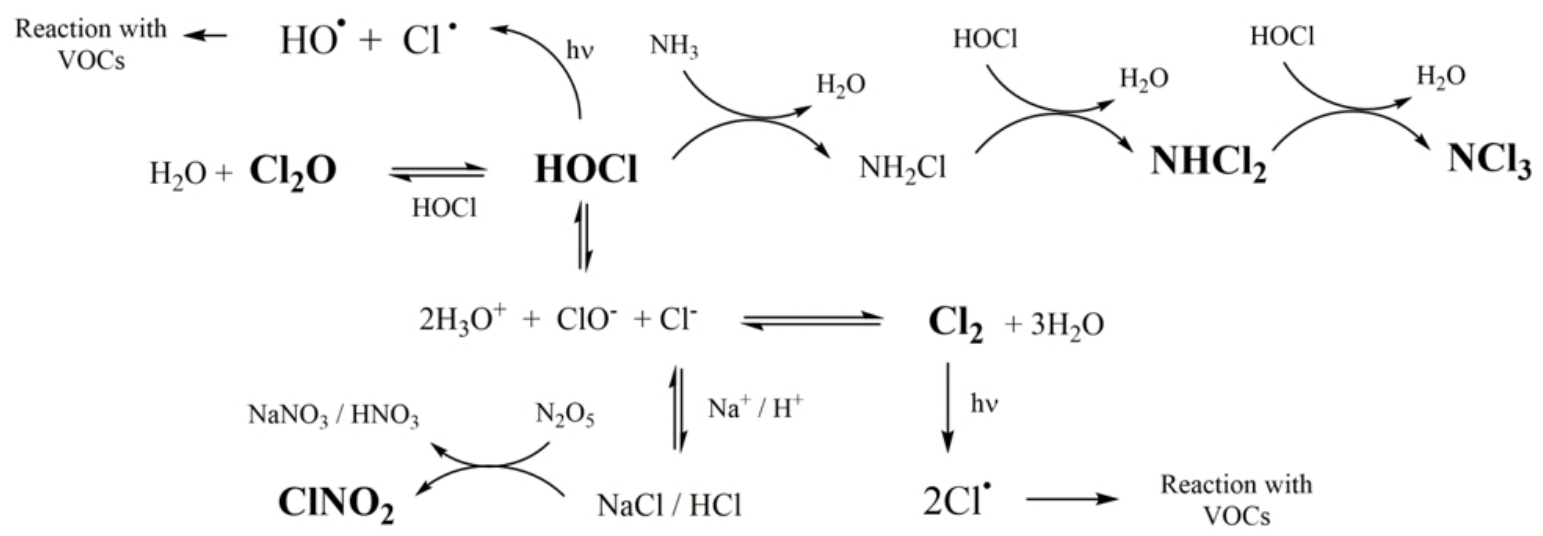

Figure 1. Detailed mechanism of indoor chemistry involving chlorine species. Species in bold were detected by the CIMS.

This article is protected by copyright. All rights reserved. 


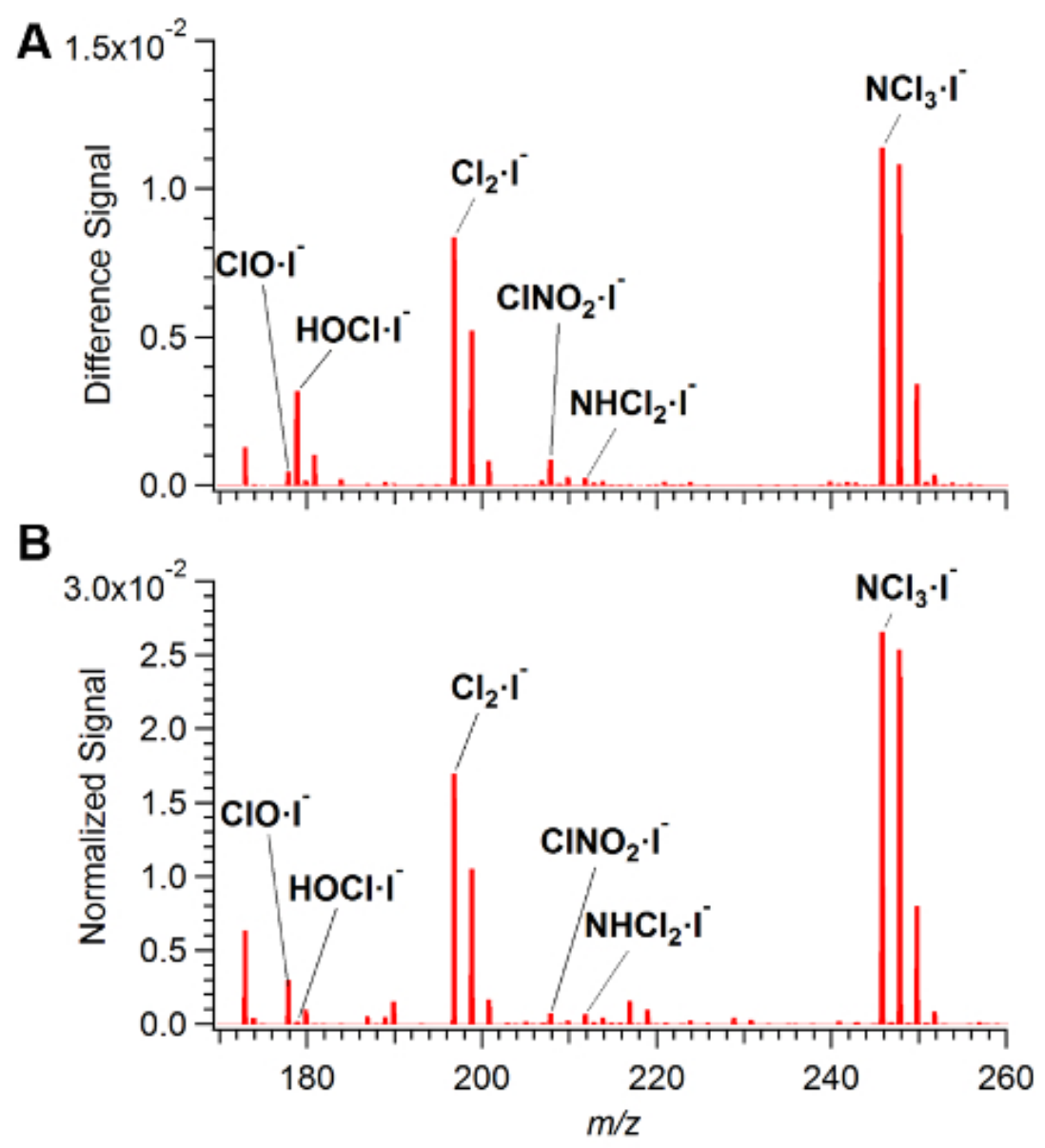

Figure 2. Typical iodide CIMS spectrum of (A) room air during a bleach mopping experiment and (B) the headspace from the bleach solution, using signals normalized by the reagent ion intensity. For (A), the signal plotted is the difference spectrum from before and after mopping, with positive signals indicative of an increase in signal.

This article is protected by copyright. All rights reserved. 


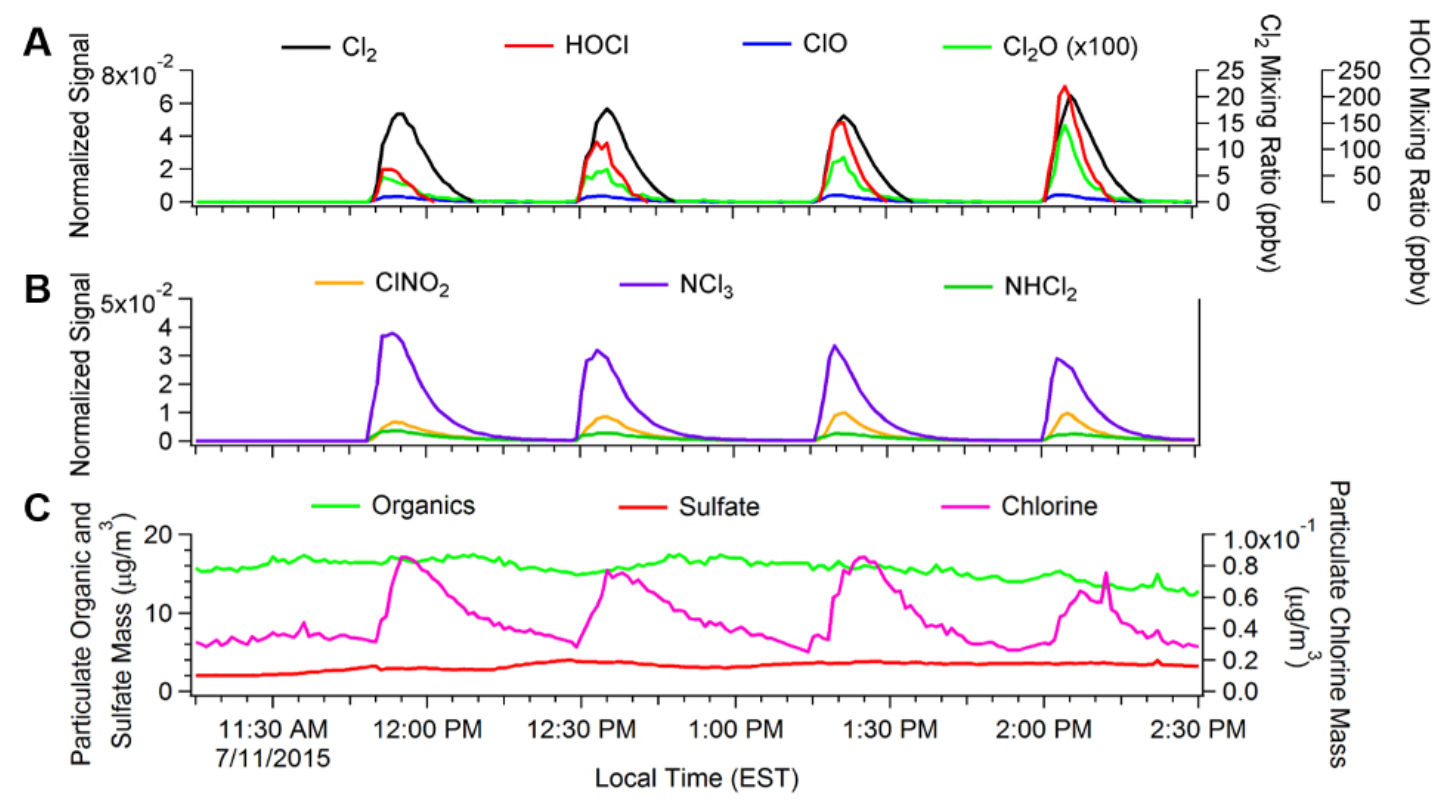

Figure 3. Time profiles of gaseous signals ( $A$ and $B$ ) and aerosol particulate signals (C) during a typical mopping experiment. Mopping was conducted with water once at the start of the experiment (11:19 AM) and with bleach four times subsequently. The mixing ratios of $\mathrm{HOCl}$ and $\mathrm{Cl}_{2}$ are provided in Figure 3A. As discussed in the text, the particulate chlorine mass is dependent on the assumed value for relative ionization efficiency of chlorinated species in the AMS (here taken to be 1.3). Note that the $\mathrm{Cl}_{2} \mathrm{O}$ trace in (A) was multiplied by 100 .

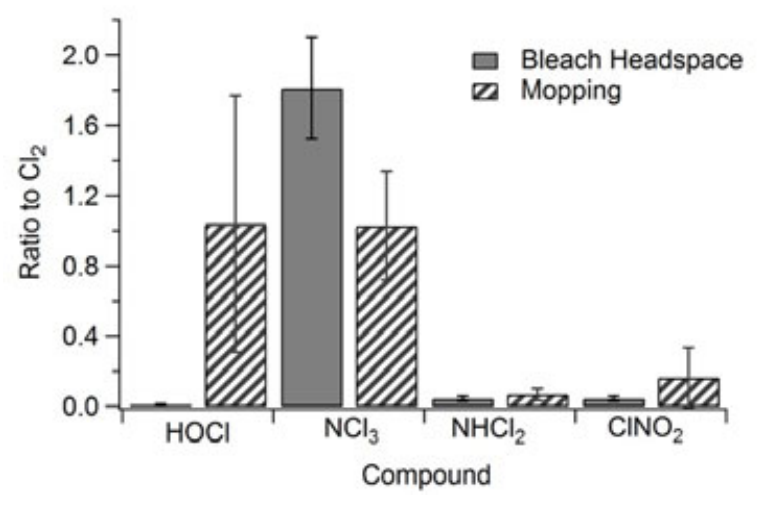

Figure 4. The average ratios of the signals of various species to $\mathrm{Cl}_{2}$, both from the headspace and the mopping experiments. The error bars represent the variability $( \pm 1 \sigma)$ between multiple experiments.

This article is protected by copyright. All rights reserved. 


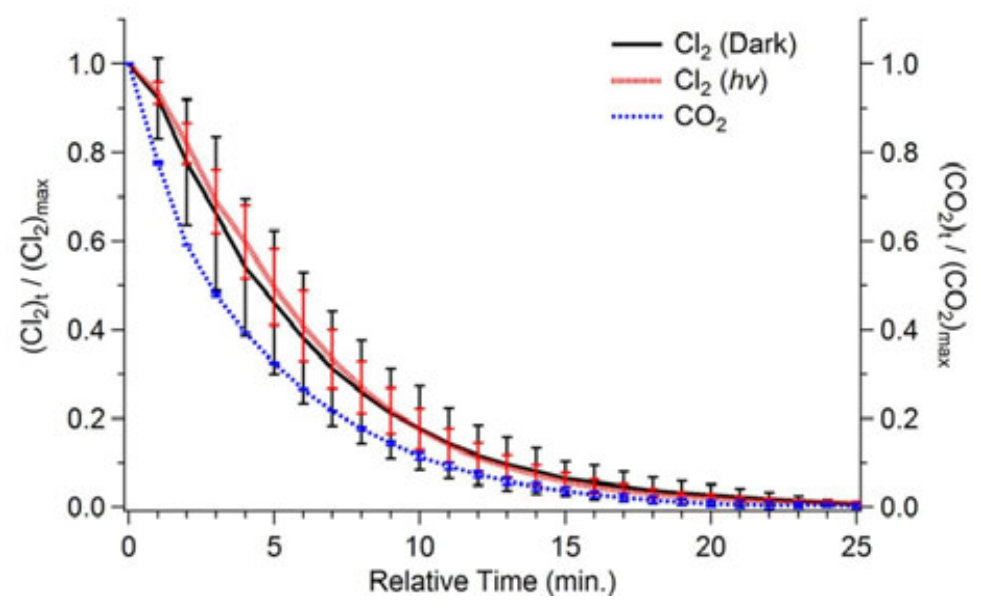

Figure 5. Plot of the $\mathrm{Cl}_{2}$ signal normalized to its maximum value during a mopping experiment, as a function of time. Data are averaged for all experiments conducted and grouped by whether there was light present in the room or not. The error bars represent the variability $( \pm 1 \sigma)$ between multiple experiments.

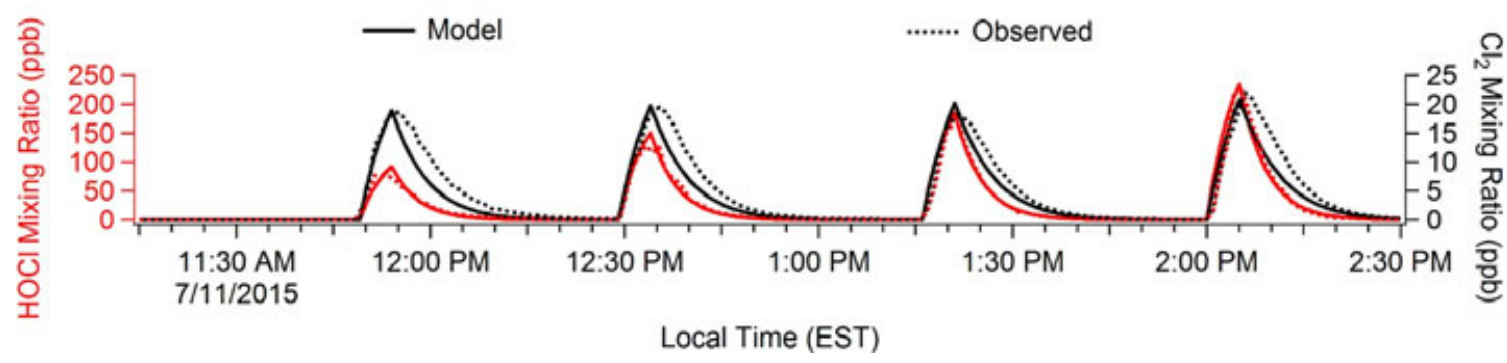

Figure 6. Plot of modeled and measured mixing ratios of $\mathrm{HOCl}$ and $\mathrm{Cl}_{2}$ (see text for details).

This article is protected by copyright. All rights reserved. 


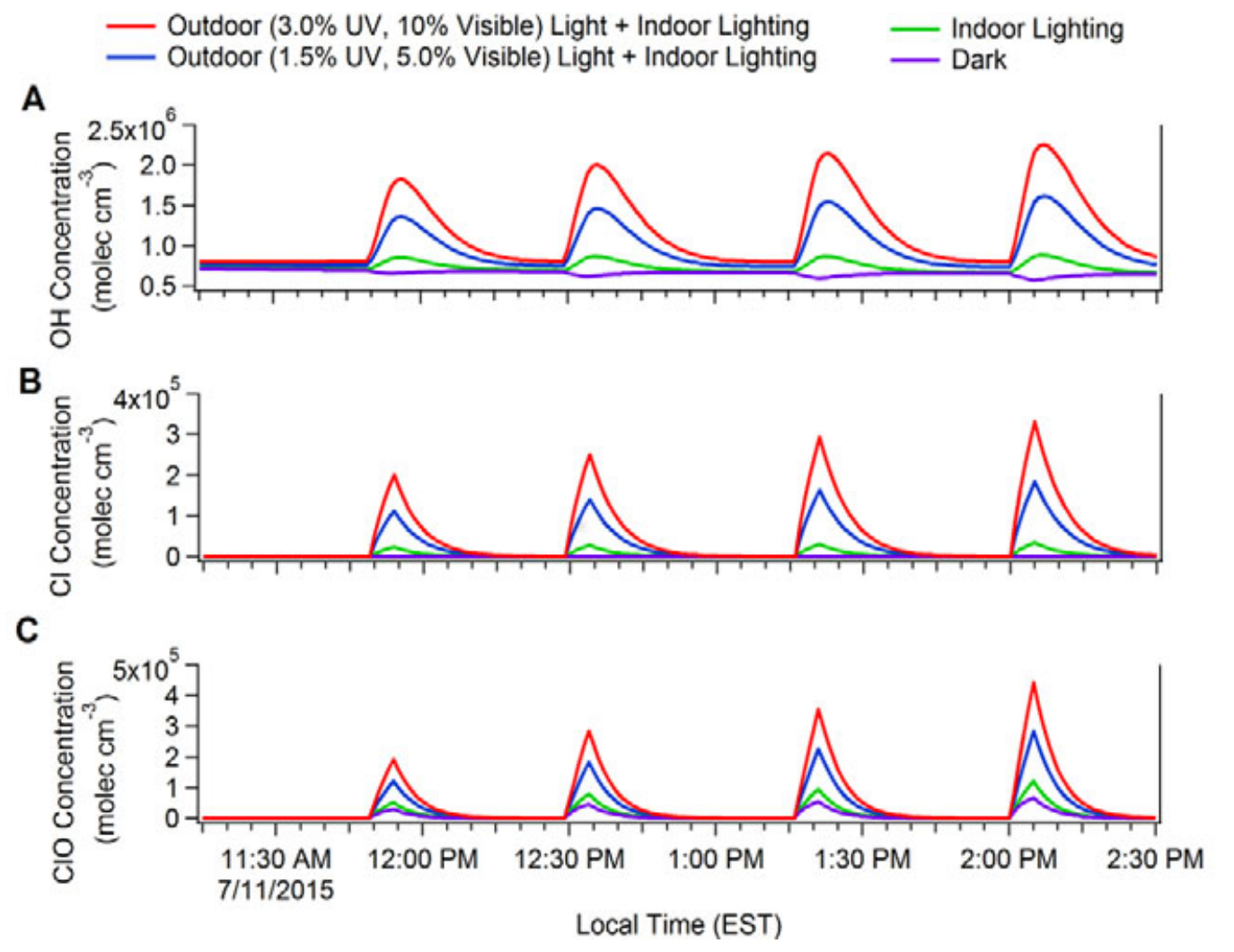

Figure 7. Plot of modeled free radical concentrations under different light scenarios (see text for details), for the model output presented in Figure 6.

This article is protected by copyright. All rights reserved. 
$1^{\text {st }}$ Order Decay Rate Constants $\left(10^{-3}, \mathrm{~s}^{-1}\right)$

$\begin{array}{cccc}\text { Compound } & \text { Dark } & \text { Room Light } & \begin{array}{c}\text { Room Light }+ \\ \text { Sunlight }\end{array} \\ & (\mathrm{N}=4) & (\mathrm{N}=3) & - \text { - }=5) \\ \mathrm{CO}_{2} & 3.54 \pm 0.08 & -- & 3.11 \pm 0.72 \\ \mathrm{Cl}_{2} & 3.17 \pm 0.90 & 2.99 \pm 0.31 & 5.01 \pm 1.21 \\ \mathrm{HOCl} & 4.85 \pm 1.86 & 5.11 \pm 0.55 & 5.40 \pm 1.30 \\ \mathrm{ClO} & 4.75 \pm 2.54 & 7.13 \pm 0.67 & 2.72 \pm 0.30 \\ \mathrm{Cl}_{2} \mathrm{O} & 2.75 \pm 0.69 & 3.00 \pm 0.24 & 2.59 \pm 0.62 \\ \mathrm{ClNO}_{2} & 2.46 \pm 0.37 & 2.35 \pm 0.15 & 1.83 \pm 0.33 \\ \mathrm{NHCl}_{2} & 2.04 \pm 0.48 & 2.23 \pm 1.07 & 3.12 \pm 0.59 \\ \mathrm{NCl}_{3} & 3.37 \pm 0.72 & 2.83 \pm 1.33 & 2.30 \pm 0.32\end{array}$

Table 1. First-order decay rate constants for different species, after a mopping experiment. The uncertainties for each rate constant are $\pm 1 \sigma$, and the number of replicate experiments for each mopping experiment $(\mathrm{N})$ is indicated.

This article is protected by copyright. All rights reserved. 


\begin{tabular}{|c|c|c|c|}
\hline Condition & Date of Expt & $\mathrm{Cl}_{2}(p p b v \min )$ & $\mathrm{HOCl}(p p b v \min )$ \\
\hline \multirow[t]{4}{*}{ Dark } & 7/4/2015 (\#1) & 230 & 1992 \\
\hline & $7 / 4 / 2015(\# 2)$ & 246 & 2507 \\
\hline & 7/11/2015 (\#1) & 211 & 697 \\
\hline & $7 / 11 / 2015(\# 2)$ & 206 & 1073 \\
\hline \multirow[t]{3}{*}{ Room Light Only } & $7 / 4 / 2015$ (\#3) & 301 & 3666 \\
\hline & 7/4/2015 (\#4) & 319 & 4318 \\
\hline & $7 / 4 / 2015$ (\#5) & 363 & 5255 \\
\hline \multirow[t]{5}{*}{ Room Light + Ambient } & 6/16/2015 (\#1) & 445 & 2071 \\
\hline & $6 / 16 / 2015(\# 2)$ & 461 & 3160 \\
\hline & 6/16/2015 (\#3) & 422 & 3312 \\
\hline & $7 / 11 / 2015$ (\#3) & 191 & 1215 \\
\hline & $7 / 11 / 2015(\# 4)$ & 221 & 1584 \\
\hline
\end{tabular}

Table 2. Integrated areas of $\mathrm{Cl}_{2}$ and $\mathrm{HOCl}$ signals, after each mopping experiment. The order in which each experiment was conducted on each day is indicated in brackets.

This article is protected by copyright. All rights reserved. 